\title{
A dynamic approach to estimate the probability of exposure of marine predators to oil exploration seismic surveys over continental shelf waters
}

\author{
Luis A. Hückstädt ${ }^{1, *}$, Lisa K. Schwarz ${ }^{2}$, Ari S. Friedlaender ${ }^{1}$, Bruce R. Mate ${ }^{3}$, \\ Alexandre N. Zerbini ${ }^{4,5,6}$, Amy Kennedy ${ }^{4}$, Jooke Robbins ${ }^{7}$, Nicolas J. Gales ${ }^{8}$, \\ Daniel P. Costa ${ }^{1,9}$
}

\author{
${ }^{1}$ Institute of Marine Sciences, University of California Santa Cruz, Santa Cruz, CA 95060, USA \\ ${ }^{2}$ Department of Ocean Sciences, University of California Santa Cruz, Santa Cruz, CA 95064, USA \\ ${ }^{3}$ Marine Mammal Institute, Oregon State University, Newport, OR 97365, USA \\ ${ }^{4}$ Joint Institute for the Study of Atmosphere and Ocean (JISAO), \\ University of Washington \& Marine Mammal Laboratory, NOAA, Seattle, WA 98112, USA \\ ${ }^{5}$ Marine Ecology and Telemetry Research, Seabeck, WA, 98380, USA \\ ${ }^{6}$ Instituto Aqualie, Juiz de Fora, MG, Brazil \\ ${ }^{7}$ Center for Coastal Studies, Provincetown, MA 02657, USA \\ ${ }^{8}$ Australian Antarctic Division, Kingston, Tasmania 7050, Australia \\ ${ }^{9}$ Department of Ecology and Evolutionary Biology, University of California Santa Cruz, Santa Cruz, CA 95060, USA
}

\begin{abstract}
The ever-increasing human demand for fossil fuels has resulted in the expansion of oil exploration efforts to waters over the continental shelf. These waters are largely utilized by a complex biological community. Large baleen whales, in particular, utilize continental shelf waters as breeding and calving grounds, foraging grounds, and also as migration corridors. We developed a dynamic approach to estimate the likelihood that individuals from different populations of blue whales Balaenoptera musculus and humpback whales Megaptera novaeangliae could be exposed to idealized, simulated seismic surveys as they move over the continental shelf. Animal tracking data for the different populations were filtered, and behaviors (transit and foraging) were inferred from the tracks using hidden Markov models. We simulated a range of conditions of exposure by having the source of noise affecting a circular area of different radii $(5,25,50$ and $100 \mathrm{~km})$, moving along a gridded transect of 270 and $2500 \mathrm{~km}^{2}$ at a constant speed of $9 \mathrm{~km} \mathrm{~h}^{-1}$, and starting the simulated surveys every week of the year. Our approach allowed us to identify the temporal variability in the susceptibility of the different populations under study, as we ran the simulations for an entire year, allowing us to identify periods when the surveys would have an intensified effect on whales. Our results highlight the importance of understanding the behavior and ecology of individuals in a site-specific context when considering the likelihood of exposure to anthropogenic disturbances, as the habitat utilization patterns of each population are highly variable.
\end{abstract}

KEY WORDS: Disturbance $\cdot$ Ocean noise $\cdot$ Blue whale $\cdot$ Humpback whale Satellite tracking Continental shelf

\section{INTRODUCTION}

Coastal waters, defined here as the waters between the coastline and the edge of the continental shelf, are highly productive regions within the global

${ }^{*}$ Corresponding author: lahuckst@gmail.com ocean that support complex marine ecosystems (Ray 1988, Sherman 1994). A large proportion of the human population lives along the coastline and relies heavily on coastal waters for a diversity of activities, which makes coastal marine ecosystems particularly

() The authors 2020. Open Access under Creative Commons by Attribution Licence. Use, distribution and reproduction are unrestricted. Authors and original publication must be credited. 
vulnerable to anthropogenic pressures (Costanza 1999), including pollution, overfishing, anthropogenic noise and many others (Jackson 2001, Halpern et al. 2008, 2015).

The high demand for fossil fuel (oil and natural gas), along with the rapid technological advances in their exploration and extraction, has created a pressing need to assess the consequences that these activities have on marine ecosystems, particularly in the continental shelf region (but see Merrie et al. 2014). Seismic surveys, an important tool for locating underwater petroleum deposits, are sources of high-intensity, potentially far-reaching, low-frequency noise in the ocean (Nowacek et al. 2015, Harwood et al. 2016). Furthermore, these activities have expanded into higher latitudes as polar sea ice retreats. An understanding of whether and how marine seismic surveys affect different levels of biological organization, from individuals to ecosystems, is therefore warranted (Nowacek et al. 2015).

Much of the research on the effects of humangenerated noise on aquatic organisms has focused on marine mammals (National Research 2003, Madsen 2005), as they have the most sensitive hearing and the broadest hearing range, and because they directly overlap a number of sound-generating activities such as navy sonar, shipping and seismic surveys. Marine mammals are also protected under the legislations of several countries. To that end, a series of working groups developed a conceptual framework (population consequences of disturbance [PCoD] model) to address how human-caused disturbances in marine mammals (acute or chronic) link to changes in population growth (Fig. S1 in the Supplement at www. int-res.com/articles/suppl/n042p185_supp.pdf) (National Research Council 2005, New et al. 2013, 2014, Harwood et al. 2016, National Academies of Sciences, Engineering, and Medicine 2017, Pirotta et al. 2018).

Ongoing efforts continue to improve our understanding of the model's transfer functions (mechanisms connecting exposure to a disturbance to changes in behavior, life function, vital rates and population dynamics; see National Research Council 2005, New et al. 2013), particularly with respect to the effects of lost foraging time as a result of disturbance (Goldbogen et al. 2013, King et al. 2015, Friedlaender et al. 2016). The most recent iteration of the framework (population consequences of multiple stressors [PCoMS] model) includes the likelihood of exposure as an important early step. The aforementioned probability, however, has traditionally been estimated employing a static approach using sources of disturbance fixed both in space and time (e.g.
Maxwell et al. 2013, Costa et al. 2016b, Ellison et al. 2016). Although informative, those approaches ignore the dynamic nature of an animal's behavioral and movement patterns (i.e. animals are not persistently occupying their entire range), as well as spatially and temporally dynamic sources of disturbance (e.g. military operations or seismic surveys). A more thorough understanding of exposure can be obtained by using an approach that incorporates animal movement and a dynamic source of disturbance (Costa et al. 2016a, Ellison et al. 2016).

Rorquals (family Balaenopteridae), which include the largest species of animals ever to have lived on the planet, inhabit all oceans of the world, typically breed in low latitudes and migrate to coastal highly productive, mid- and high-latitude regions to forage. Rorqual populations were severely depleted by human harvesting, but with the end of whaling during the second half of the 20th century, many populations are now recovering (Clapham et al. 1999, Thomas et al. 2016).

Some rorquals use the continental shelf waters for both migration and foraging, and are thus likely to come into conflict with human activities, particularly as a result of exposure to sources of intense, mid- to low-frequency noise (Southall et al. 2012). Furthermore, ocean noise is particularly relevant to rorquals as they rely heavily on sound for important aspects of their biology (Harwood 2001, Van der Hoop et al. 2013, Nowacek et al. 2015, Thomas et al. 2016). Indeed, an important effort has been directed towards enhancing our understanding of how noise exposure elicits changes in the behavior of individuals (behavioral response studies) (Southall et al. 2012, 2016, Goldbogen et al. 2013, Friedlaender et al. 2016).

Because of their large size, high energetic demands and life histories, rorquals range over broad, basin-wide areas, and thus the likelihood of their exposure to a disturbance will vary in both space and time. In this study, we used animal movement data collected from different populations of blue (Balaenoptera musculus) and humpback whales (Megaptera novaengliae) across the globe to estimate whether and for how long individuals from a population would be exposed to a series of simulated, idealized seismic surveys, assuming the exposure does not elicit any behavioral modifications. Our model provides a data-derived empirical view of how a moving source of disturbance could impact individuals as they move throughout their environment, which allows us to describe the spatial and temporal variability in the potential impacts of seismic surveys at the individual (behavioral state) level as well as the proportion of individuals affected. 


\section{MATERIALS AND METHODS}

\subsection{Animal movement data}

We compiled movement data for blue and humpback whales from 8 areas of the world, representing 2 and 6 distinct populations of blue and humpback whales, respectively (Table 1, Fig. 1). Some of these data sets have been analyzed and published elsewhere (Zerbini et al. 2006, 2011, Bailey et al. 2009, de Castro et al. 2014, Irvine et al. 2014, Kennedy et al. 2014, Weinstein et al. 2018). These areas were chosen based on the availability of animal tracking data, rather than their likelihood of being subject to actual surveys, as the purpose of this initial modeling exercise was to incorporate a dynamic approach and apply it to species of different behavior, rather than to address the potential of exposure in specific areas. In this study, we define exposure as the overlap, in space and time, between the location of a particular individual and a circle of determined radius representing the area affected by the simulated seismic survey (see Fig. 2 and Section 2.2).

Table 1. Movement data summaries for blue and humpback whale tracking data sets included in the study. HR: high residence behavior; LR: low residence behavior

\begin{tabular}{|c|c|c|c|c|c|c|}
\hline Species & Site & $\mathrm{N}$ & $\begin{array}{c}\text { Days } \\
\text { transmitting }\end{array}$ & $\begin{array}{c}\text { Time over shelf } \\
\text { waters }(\%)\end{array}$ & $\% \mathrm{HR}$ & $\%$ LR \\
\hline \multirow[t]{2}{*}{ Blue whale } & California Current & 104 & $6-504$ & 20.3 & 83.6 & 16.4 \\
\hline & Western Australia & 10 & $7-179$ & 9.7 & 76.5 & 23.5 \\
\hline \multirow[t]{6}{*}{ Humpback whale } & Bering Sea & 8 & $9-94$ & 66.2 & 56.9 & 43.1 \\
\hline & California Current & 12 & $3-122$ & 51.1 & 31.2 & 68.8 \\
\hline & Antarctic Peninsula & $24^{\mathrm{a}}$ & $5-210$ & 77.3 & 89.3 & 10.7 \\
\hline & Gulf of Maine & 55 & $2-112$ & 96.7 & 68.9 & 31.1 \\
\hline & Southwest Atlantic & 12 & $8-284$ & 14.2 & 84.6 & 15.4 \\
\hline & Eastern Australia & 30 & $3-154$ & 23.6 & 65.8 & 34.2 \\
\hline
\end{tabular}

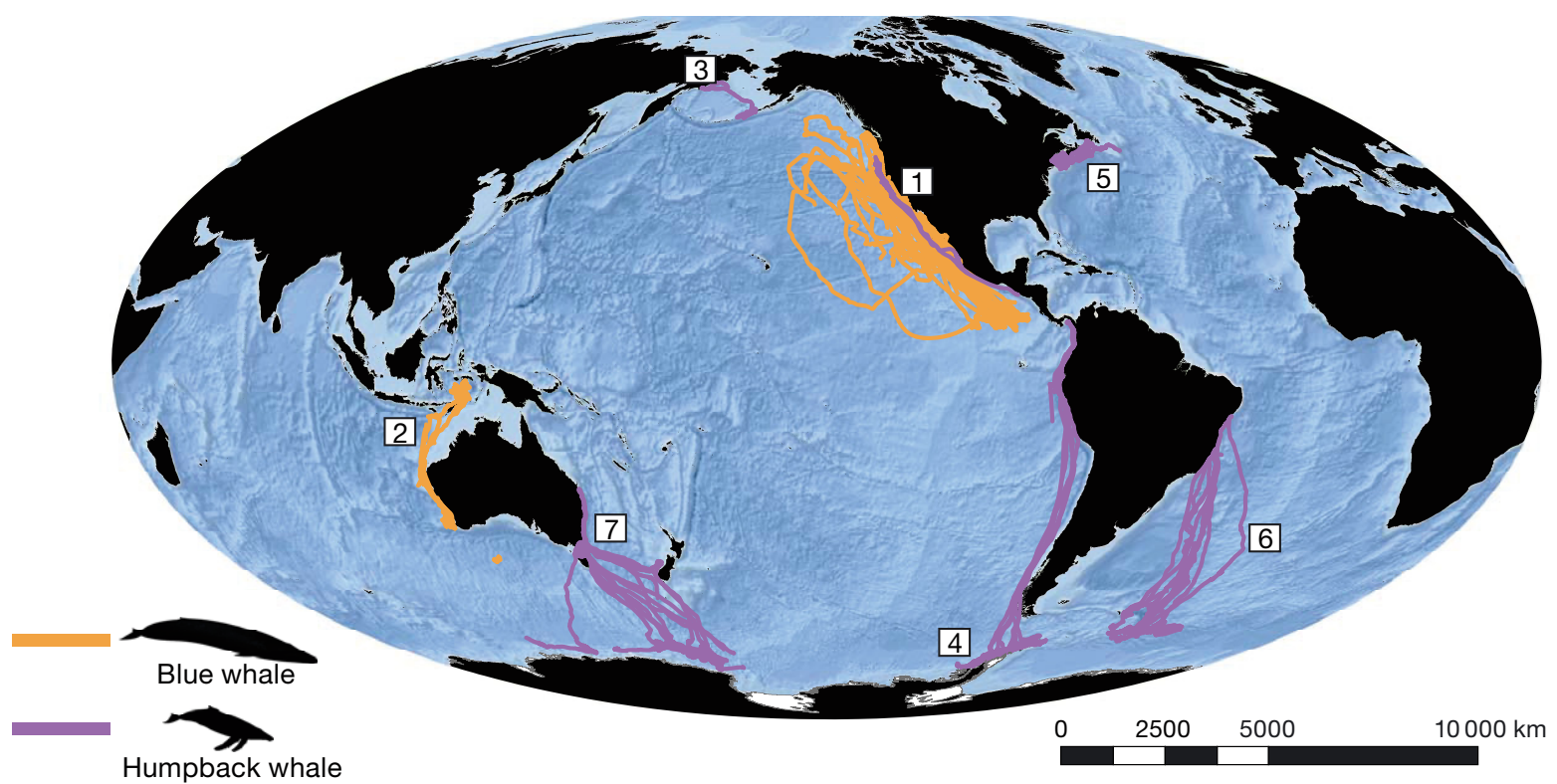

Fig. 1. Individual tracks of blue whales (yellow) and humpback whales (purple) included in this study. The numbers on the map correspond to the different regions. Blue whale tracking data sets were collected in the California Current $(1: \mathrm{CalCur}, \mathrm{n}=104)$ and Western Australia (2: WesAus, $\mathrm{n}=10)$. Humpback whale tracking data sets were collected in the Bering Sea $(3:$ BerSea, $\mathrm{n}=8)$, California Current (1: CalCur, $\mathrm{n}=12$ ), Antarctic Peninsula (4: AntPen, $\mathrm{n}=24$ ), Gulf of Maine (5: GulMai, $\mathrm{n}=55$ ), Southwest Atlantic (6: SouAtl, $\mathrm{n}=12$ ) and Eastern Australia ( 7 : EasAus, $\mathrm{n}=30$ ) 
Animal tracking data were collected and transmitted using the Argos satellite system (Toulousse, France). All raw tracking data were analyzed in $\mathrm{R}$ 3.1 (R Development Core Team 2019). First, data were pre-processed using a speed filter to remove evident erroneous positions (McConnell et al. 1992) and later processed with a continuous-time correlated random walk model (crawl R package) (Johnson et al. 2008) to render realistic estimates of animal movement at regular time intervals that varied by data set based on the quality of the data sets and data gaps. As the tracking data were collected over many different years and our goal was to build simulations for a period of $1 \mathrm{yr}$, all tracks were standardized to a common single year by converting to calendar day (1-365 d). As diving depth data were not available and to avoid the complications associated with modeling noise propagation in 3 dimensions (see Section 2.2), we did not consider depth in our modeling approach.

Given that the PCoD/PCoMs model focuses on changes in time-energy budget with respect to lost foraging time, it was necessary to infer behavioral states from the animal movement data. This was done by processing the crawl-processed tracking data through hidden Markov models (HMMs) to define behaviors (high residency, HR, or low residency, LR) using the package momentuHMM in R (McClintock et al. 2018). The HR behavior was characterized as sections of the tracks where animals displayed a slow transit rate and high turning rate (high tortuosity), remaining in a particular area for a prolonged amount of time (i.e. foraging or breeding, depending on the area). LR behavior, in contrast, was characterized as sections of the track where animals swam faster and with a clear directionality.

\subsection{Simulations of seismic surveys}

Given the variability in the spectrum of transect sizes and conformation of seismic surveys, we opted to define 2 types of idealized survey transect: (1) 3D survey: 85 parallel transect lines of $50 \mathrm{~km}$ in length, spaced every $600 \mathrm{~m}$; and (2) 4D survey: 100 parallel transect lines of $20 \mathrm{~km}$ in length, spaced every $200 \mathrm{~m}$ (Fig. 2). These surveys are based on the general characteristics of a 'typical seismic survey' and capture the basic movement patterns of seismic vessels, making them a realistic generic approximation of the potential of exposure. Real seismic exploration 3D surveys acquire data on a 3D grid, allowing horizontal projections in directions other than along the tran- sects, whereas $4 \mathrm{D}$ surveys can acquire the same data as 3D surveys adding the time dimension, shooting the same grid at regular intervals, allowing the generation of time series. For each population included in the study, we randomly placed 100 surveys of each type over the continental shelf waters that were utilized by the whales (as identified from kernel home range analysis).

Due to the inherent complexity of sound propagation for different ocean basins and continental margins, and the need to come up with general patterns that could be applied to a variety of environments, we chose to simulate the area of exposure as a horizontal circle of different radii $(5,25,50$ and $100 \mathrm{~km})$, as these radii encompass the most reasonable range of distances that could elicit a behavioral response by animals to seismic surveys (Nowacek et al. 2015) (Fig. 2). These simulated sources moved along the grid at a constant speed of $9 \mathrm{~km} \mathrm{~h}^{-1}$ (ca. 4.5 - 5 knots), accounting for a lag of $3 \mathrm{~h}$ when switching survey lines when no sound emissions were active. To incorporate the temporal variability in the tracking data and movement patterns of the individuals, we set the first day of every week of the year (i.e. 52) as the start time for every combination of survey and radius. Therefore, for each population, we had a total of 100 surveys $\times 2$ survey types $\times 4$ radii of exposure $\times 52 \mathrm{wk}$, totaling 41600 simulations.

Finally, all animal movement data were interpolated at a regular time interval $(1 \mathrm{~h})$ and the spatial overlap between the area of influence of the simulated survey and the animals' location was calculated. From this overlap, we were able to calculate the proportion of the tagged individuals exposed, the total time each individual was exposed, and the amount of exposure time for each behavior.

Each one of these variables was estimated for standardized periods of $1 \mathrm{wk}$, obtaining (1) the proportion of the tagged individuals under exposure per week; (2) the number of animal hours of exposure per week (maximum $168 \mathrm{~h}$ ); (3) the number of animal exposure hours in LR behavioral state per week (maximum $168 \mathrm{~h}$ ); and (4) the number of animal exposure hours in HR behavioral state per week (maximum 168 h).

\section{RESULTS}

We ran a total of 41600 possible combinations of surveys (4D and 3D) and radii of exposure (5, 25, 50 and $100 \mathrm{~km}$ ) for 2 populations of blue whales and 6 populations of humpback whales. 


\title{
1. Track processing
}

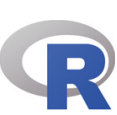

Raw Argos tracking data

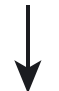

crawl

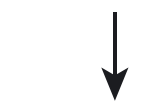

momentuHMM

2. Survey design

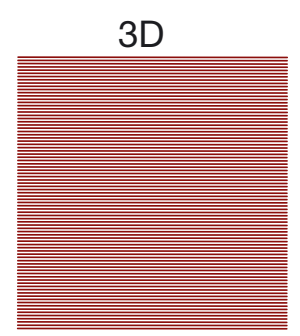

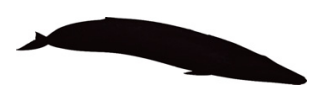
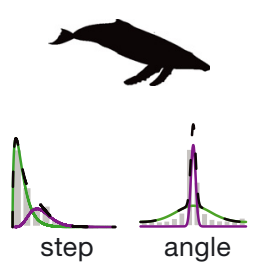

$\times 100$

$10 \mathrm{~km}$

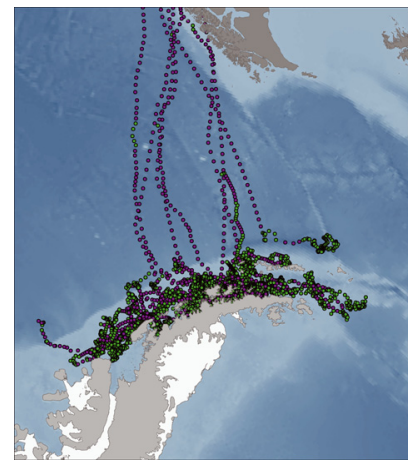

Filtered tracks with behavior (high residence [green] and low residence [purple])

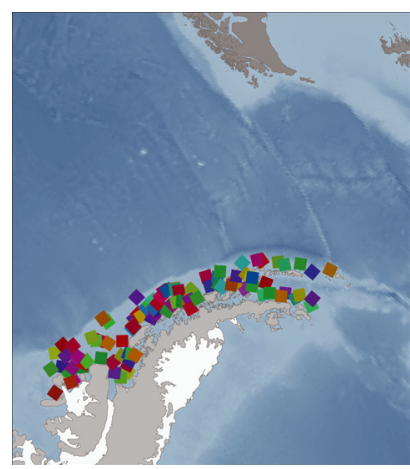

Randomly placed on utilized shelf waters

3. Spatial and temporal variability of disturbance

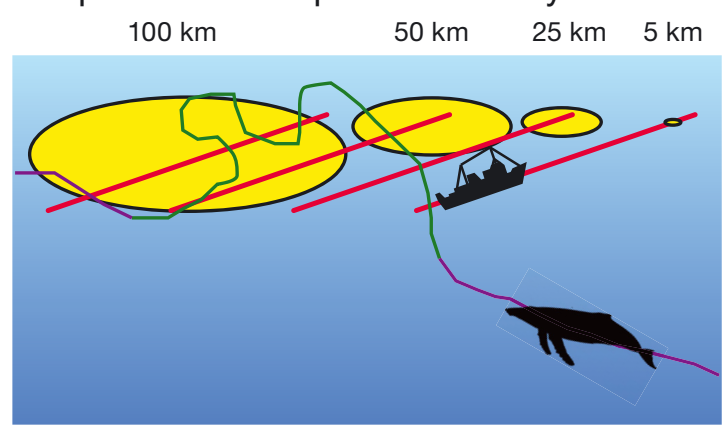

\author{
Survey start (calendar day) \\ $1,8,15,22, \ldots, 348$

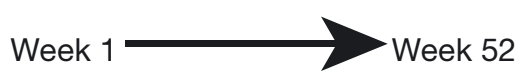

4. Exposure at the individual and tagged population level

$\sum$ Time under exposure

$\mathrm{N}_{\text {ind }}$

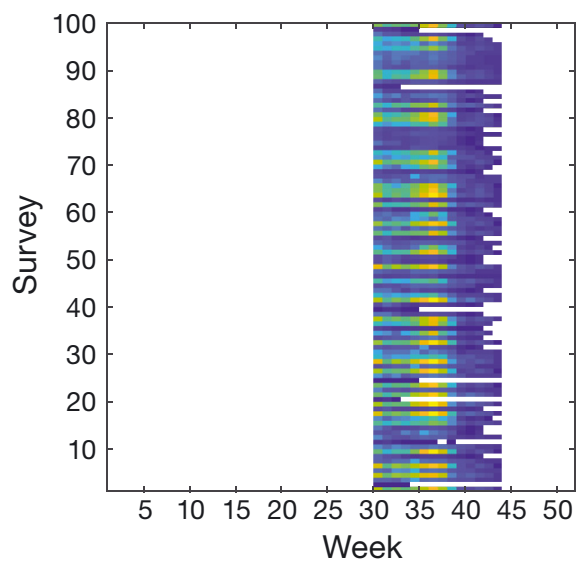

Fig. 2. Simulation approach used to estimate the probability and duration of exposure to seismic surveys across different populations of blue $(\mathrm{N}=2)$ and humpback whales $(\mathrm{N}=6)$. In Step 3, red lines show transects and yellow ovals show exposure radii. In Step 4, sigma corresponds to the sum of time across individuals; the colors refer to exposure intensity or the mean individual time under exposure (see Fig. 5), with warmer colors indicating longer exposures 


\subsection{Movement patterns}

There were clear differences in the patterns of movement and habitat utilization among populations. As reported previously, blue whales (California Current and Western Australia) spent the majority of their time off the continental shelf (Fig. 1 and Table 1) (Bailey et al. 2009, Double et al. 2014, Irvine et al. 2014). However, the time spent on the continental shelf was predominantly identified as HR behavior, likely indicating that they were foraging in those waters.

While most of the humpback whales were tagged on their foraging grounds (Bering Sea, California Current, Antarctic Peninsula, and the Gulf of Maine), individuals from 2 populations (Southwest Atlantic and Eastern Australia) were tagged at their low-latitude breeding grounds or along their transit towards their high-latitude foraging grounds (Table 1, Fig. 1). As expected, individuals migrating across ocean basins spent the least amount of the time over continental shelves (14.2 and $23.6 \%$ for individuals from the Southwest Atlantic and Eastern Australian populations, respectively; Table 1). The remaining humpback whale populations exhibited a pattern that was largely associated with waters over continental shelves, or close to the continental shelf break (e.g. California Current) (Fig. 1). Tracking data for some individuals tagged in the Antarctic Peninsula were sufficiently long to record their migration to breeding grounds in the Eastern Equatorial Pacific. For this population, we restricted the analysis to areas within $500 \mathrm{~km}$ of the edge of the Antarctic continental shelf.

\subsection{Behavioral states}

The behavioral categorization using HMMs showed similarity in the movements within species. Most data sets presented a clear distinction between the 2 defined behaviors (HR and LR), although blue whales off the California Current system departed from this binary definition of behaviors and showed instead a more complex scenario, with more plausible solutions of the HMMs distinguishing at least 3 behaviors (not shown here). Yet, since our aim was to compare across the different populations rather than analyze the movement and behavioral patterns of each population, we opted to use the 2-behavioral states output for consistency across the study sites.

With the exception of humpback whales in the California Current, all whales spent the majority of their time over continental shelf waters engaged in HR behavior (56.9-89.3\%) (Table 1).

\subsection{Simulated exposures}

The number of randomly placed surveys that implied exposure to the different populations of whales varied widely across populations, with a minimum of ten $4 \mathrm{D}$ surveys with a radius of $5 \mathrm{~km}$ for the blue whales from Western Australia, and a maximum of 100 3D surveys with a radius of $100 \mathrm{~km}$ for the humpback whales tagged in the Bering Sea.

\subsection{Proportion of individuals experiencing exposure}

The proportion of the tagged individuals that overlapped with seismic surveys varied widely across the species and sites. Irrespective of the survey type or the radius of influence, the probability of exposure for blue whales in the California Current and humpback whales off both the Antarctic Peninsula and Eastern Australia was consistently low (75th percentile < 0.13). In contrast, humpback whales from the Bering Sea consistently exhibited the highest proportion of tracks overlapping with seismic surveys (25th percentile $=0.31$, 75th percentile $=0.81$ ), followed by humpback whales in the California Current (Fig. 3).

Despite the differences in the area and duration of exposure between $4 \mathrm{D}$ and 3D surveys, the proportion of tagged individuals that were affected did not differ

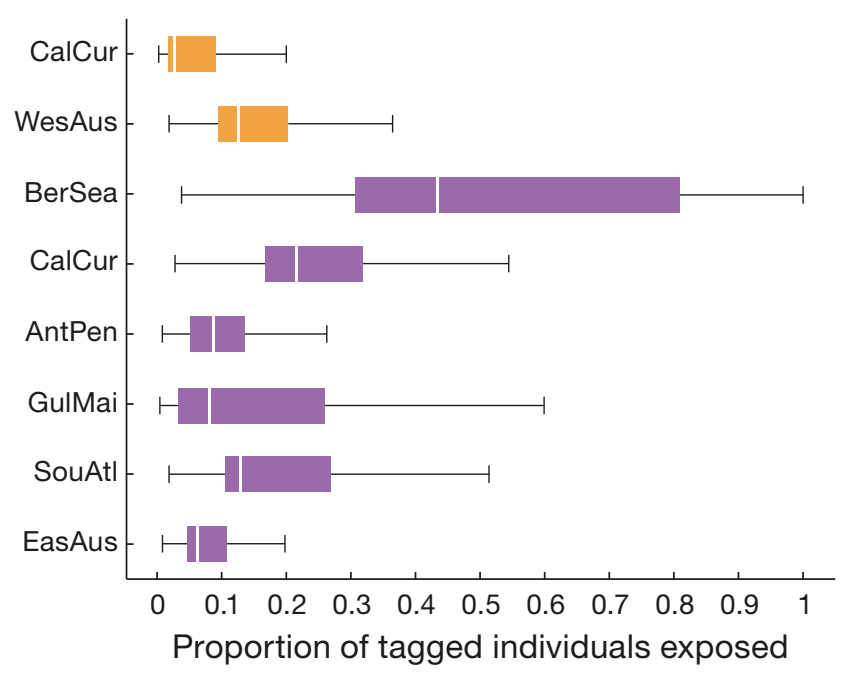

Fig. 3. Proportion of the tagged individuals of blue whales (yellow) and humpback whales (purple) exposed to simulated seismic survey per site (for site abbreviations, see Fig. 1 legend). Data for all combinations of survey design (4D and 3D) and radii of influence $(5,25,50$ and $100 \mathrm{~km})$ were pooled together. The white line represents the median. The edges of the boxes represent the 25 th and 75 th percentiles, and the lines represent the 5th and 95th percentiles 


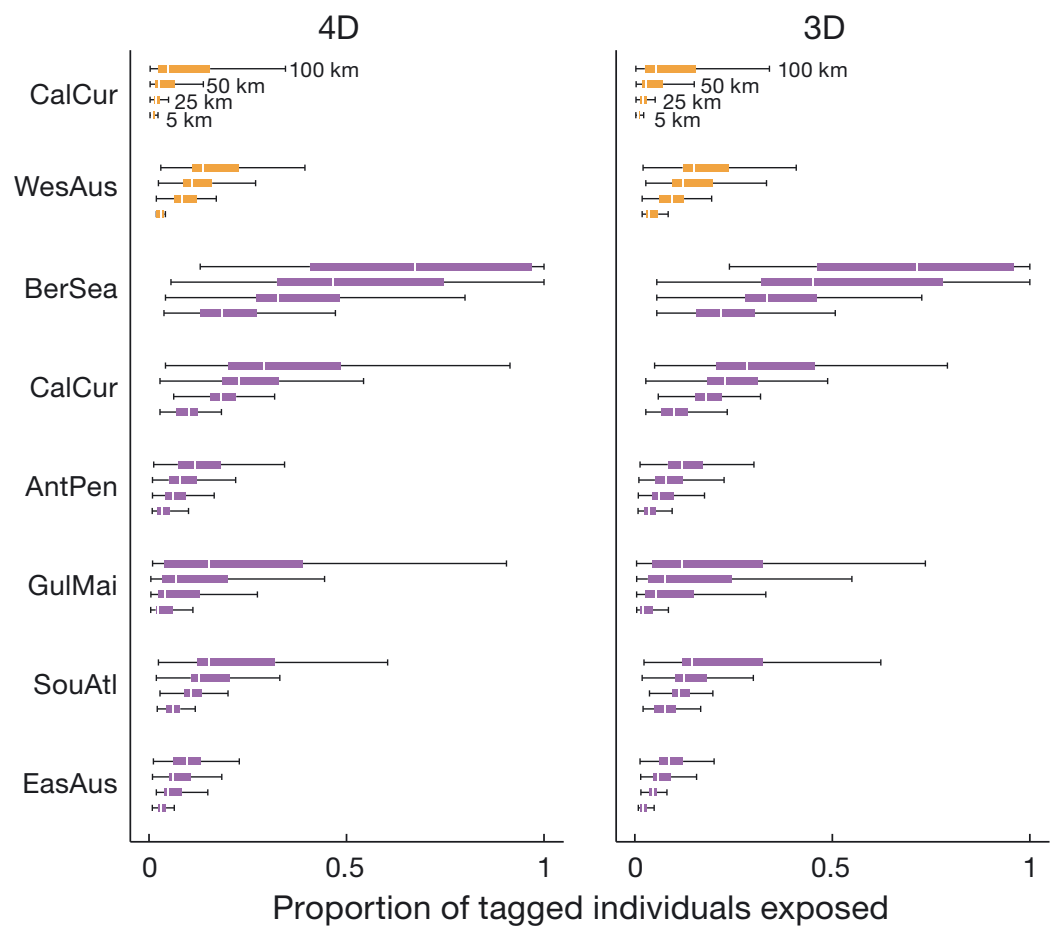

Fig. 4. Proportion of the tagged individuals of blue whales (yellow) and humpback whales (purple) exposed to simulated seismic survey per site (for site abbreviations, see Fig. 1 legend), survey and radius of influence. The white line represents the median. The numbers beside the bars (shown for CalCur) correspond to the different radii of influence used in the simulations. The edges of the boxes represent the 25 th and 75 th percentiles, and the lines represent the 5th and 95th percentiles

greatly between the survey designs (Fig. 4). There were, however, differences in the effect of increasing radii of influence across sites. For instance, the median probability of exposure for humpback whales from Eastern Australia with 3D surveys only increased from 0.02 to 0.09 for a 5 and $100 \mathrm{~km}$ radius, respectively. In contrast, the same increase in the radius of exposure for humpback whales from the Bering Sea resulted in an increase in the median probability from 0.22 to 0.71 (Fig. 4).

\subsection{Individual time and behavior under exposure}

We calculated the mean individual duration $\left(\mathrm{h} \mathrm{wk}^{-1}\right)$ of the simulated exposure affecting each behavioral state (HR or LR), an indicator of the worstcase possible scenario as we assumed that whales do not leave the affected area (Table 2). When all possible combinations of surveys and radii are included in the analysis, blue whales from Western Australia had the shortest mean individual exposure to the simulated seismic surveys (median $=$ $11.71 \mathrm{~h} \mathrm{wk}^{-1}$ ), followed by humpback whales off Eastern Australia (median = $22.33 \mathrm{~h} \mathrm{wk}^{-1}$ ) and humpback whales from the South Atlantic (median = $22.50 \mathrm{~h} \mathrm{wk}^{-1}$ ). Surprisingly, increasing the radius of influence to $25 \mathrm{~km}$ implied, across all data sets, a dramatic rise in the mean individual time animals were exposed for both behaviors (HR and LR) when compared to a 5-km radius, even for areas whose tracks indicated low exposure proportions (Table 2). For instance, humpback whales from the South Atlantic went from being exposed

Table 2. Maximum number of hours of individual exposure to simulated seismic surveys (4D and 3D) across the range of blue and humpback whales. The radii of exposure considered were 5, 25, 50 and $100 \mathrm{~km}$. Grey cells indicate high residence (HR) behavior. White cells indicate low residence (LR) behavior

\begin{tabular}{|c|c|c|c|c|c|c|c|c|c|c|c|c|c|c|c|c|}
\hline \multirow{2}{*}{ Blue whale } & \multicolumn{2}{|c|}{$5 \mathrm{~km}$} & \multicolumn{2}{|c|}{$25 \mathrm{~km}$} & \multicolumn{2}{|c|}{$50 \mathrm{~km}$} & \multicolumn{2}{|c|}{$100 \mathrm{~km}$} & \multicolumn{2}{|c|}{$5 \mathrm{~km}$} & \multicolumn{2}{|c|}{$25 \mathrm{~km}$} & \multicolumn{2}{|c|}{$50 \mathrm{~km}$} & \multicolumn{2}{|c|}{$100 \mathrm{~km}$} \\
\hline & & & & & & & & & & & & & & & & \\
\hline California Current & 42 & 37 & 82 & 82 & 82 & 82 & 82 & 82 & 37 & 34 & 122 & 117 & 126 & 125 & 126 & 126 \\
\hline Western Australia & 5 & 5 & 15 & 15 & 48 & 33 & 89 & 68 & 6 & 6 & 62 & 54 & 112 & 94 & 124 & 124 \\
\hline \multicolumn{17}{|l|}{ Humpback whale } \\
\hline Bering Sea & 43 & 25 & 91 & 55 & 92 & 74 & 92 & 81 & 27 & 17 & 124 & 78 & 126 & 93 & 126 & 112 \\
\hline California Current & 30 & 11 & 82 & 49 & 83 & 71 & 83 & 81 & 22 & 8 & 118 & 60 & 126 & 97 & 126 & 126 \\
\hline Antarctic Peninsula & 18 & 18 & 90 & 90 & 92 & 92 & 93 & 93 & 26 & 23 & 121 & 113 & 126 & 125 & 126 & 125 \\
\hline Gulf of Maine & 60 & 48 & 98 & 94 & 98 & 95 & 98 & 94 & 76 & 61 & 126 & 108 & 126 & 123 & 126 & 123 \\
\hline South Atlantic & 12 & 12 & 76 & 76 & 92 & 92 & 92 & 92 & 17 & 16 & 117 & 117 & 125 & 125 & 126 & 126 \\
\hline Eastern Australia & 23 & 23 & 89 & 88 & 89 & 89 & 91 & 90 & 15 & 12 & 110 & 99 & 124 & 120 & 126 & 124 \\
\hline
\end{tabular}


$12 \mathrm{~h} \mathrm{wk}^{-1}$ in HR behavior under a 5-km 4D survey to $76 \mathrm{~h} \mathrm{wk}^{-1}$ in HR behavior under a 25-km 4D survey (Table 2). The magnitude of these increases is similar for all data sets.

\subsection{Cumulative exposure}

To better assess the effect of simulated exposure to seismic surveys, we can evaluate the relationship between the proportion of tagged individuals and mean individual time under exposure under every possible combination of survey design and radii of influence (Fig. 2). We observed 2 general patterns that are more easily described using the most extreme cases for each: blue whales in the California Current and humpback whales from the Bering Sea (Fig. 4). We did not find a relationship between the proportion of individuals exposed and the mean individual time that animals were exposed. Instead, across the different radii, we saw very high proportions of individuals under exposure and rather short exposures, whereas the longest exposures $\left(>60 \mathrm{~h} \mathrm{wk}^{-1}\right)$ correspond to proportions in the $0.3-0.6$ range (Figs. 4 \& 5). Blue whales from the California Current, in contrast, did not generally show an increase in the proportion of tagged individuals exposed beyond 0.4, regardless of the survey design, and increasing the radii or the area affected (4D versus $3 \mathrm{D}$ ) did increase the mean individual exposure time but not the proportion of individuals affected (Figs. 4 \& 5).

\subsection{Spatio-temporal patterns of disturbance}

By using a dynamic approach to estimate the probability of exposure to a disturbance under several scenarios, we can illustrate the spatial and temporal variability of exposure probability, and can then determine areas and times of enhanced susceptibility to impacts from hypothetical seismic surveys for different populations. For instance, our simulations indicated that, regardless of the radius of influence, humpback whales from Eastern Australia were consistently exposed to the simulated seismic surveys for the shortest amount of time across all sites (Fig. 5), and this held true regardless of when in the year the survey took place. On the other hand, there is a several week period during which humpback whales from the Gulf of Maine were exposed for prolonged periods (Fig. 5).

Finally, given the spatially explicit nature of our approach, it would be possible to determine areas of higher susceptibility to disturbances across the range of a given population (Fig. S2). Humpback whales from the Bering Sea had no clear spatial pattern of susceptibility across their range, both in terms of probability of exposure as well as time (and time in HR behavior) under exposure (Fig. S2). Blue whales from the California Current, in contrast, clearly present a heterogeneous spatial pattern, with areas where the susceptibility to seismic surveys increases either in terms of probability of exposure, mean individual time of exposure, or both (Fig. S2).

\section{DISCUSSION}

Underwater noise can have deleterious effects on many marine animals, an issue of particular relevance to marine mammals due, among other things, to their reliance on acoustics to communicate among conspecifics, locate food and navigate (Myrberg 1990, National Research Council 2003, 2005, Erbe 2012, Nowacek et al. 2015, Costa et al. 2016a, Ellison et al. 2016). Regardless of the consequences that exposure to seismic surveys might have on large whales (e.g. behavioral, and physiological responses), key components of understanding the effects of anthropogenic activities on these populations are realistic estimates of the encounter rate and interaction duration.

The PCoD/PCoMS framework provides an approach to describe how (acoustic) disturbances might affect marine mammals (National Research Council 2003, New et al. 2013, King et al. 2015, Costa et al. 2016a, Harwood et al. 2016), and although significant contributions have been made to define the transfer functions and parameters of the PCoD/PCoMS model, the spatial and temporal overlap between disturbance and animals (i.e. potential of exposure) has remained less explored (Costa et al. 2016a, Ellison et al. 2016). Our study provides a general assessment of the likelihood or probability of blue and humpback whales being exposed to a seismic survey in their habitat on the continental shelf, and of how that likelihood varies depending on both the behavior of the species and the radius of influence that may elicit a response. Furthermore, as we empirically estimate behavioral states from the tracking data to calculate the likelihood of exposure, we demonstrate that even in areas of lower time spent by the whales (i.e. LR behavior), seismic surveys have the potential to impact individual whales for periods similar to those seen in areas of higher usage (i.e. HR behavior). While the impacts of the exposure under different 
A
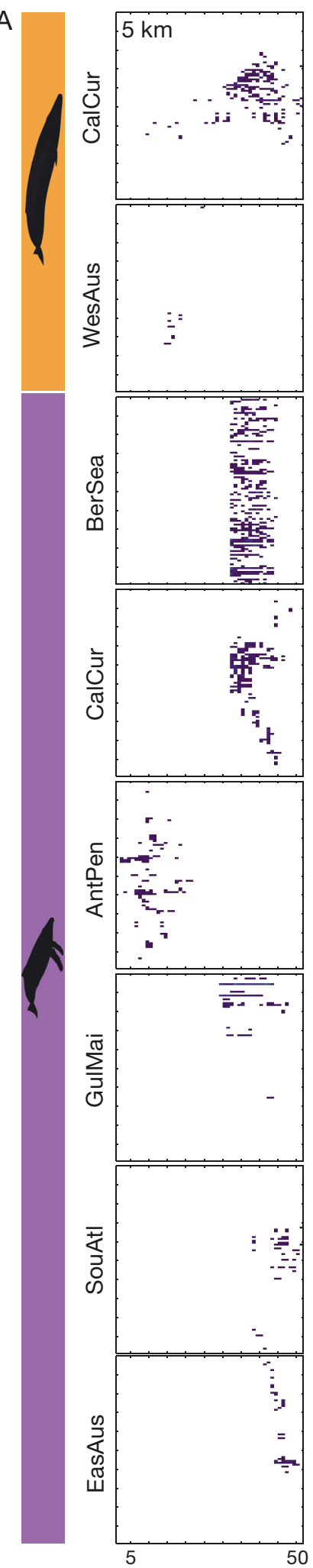
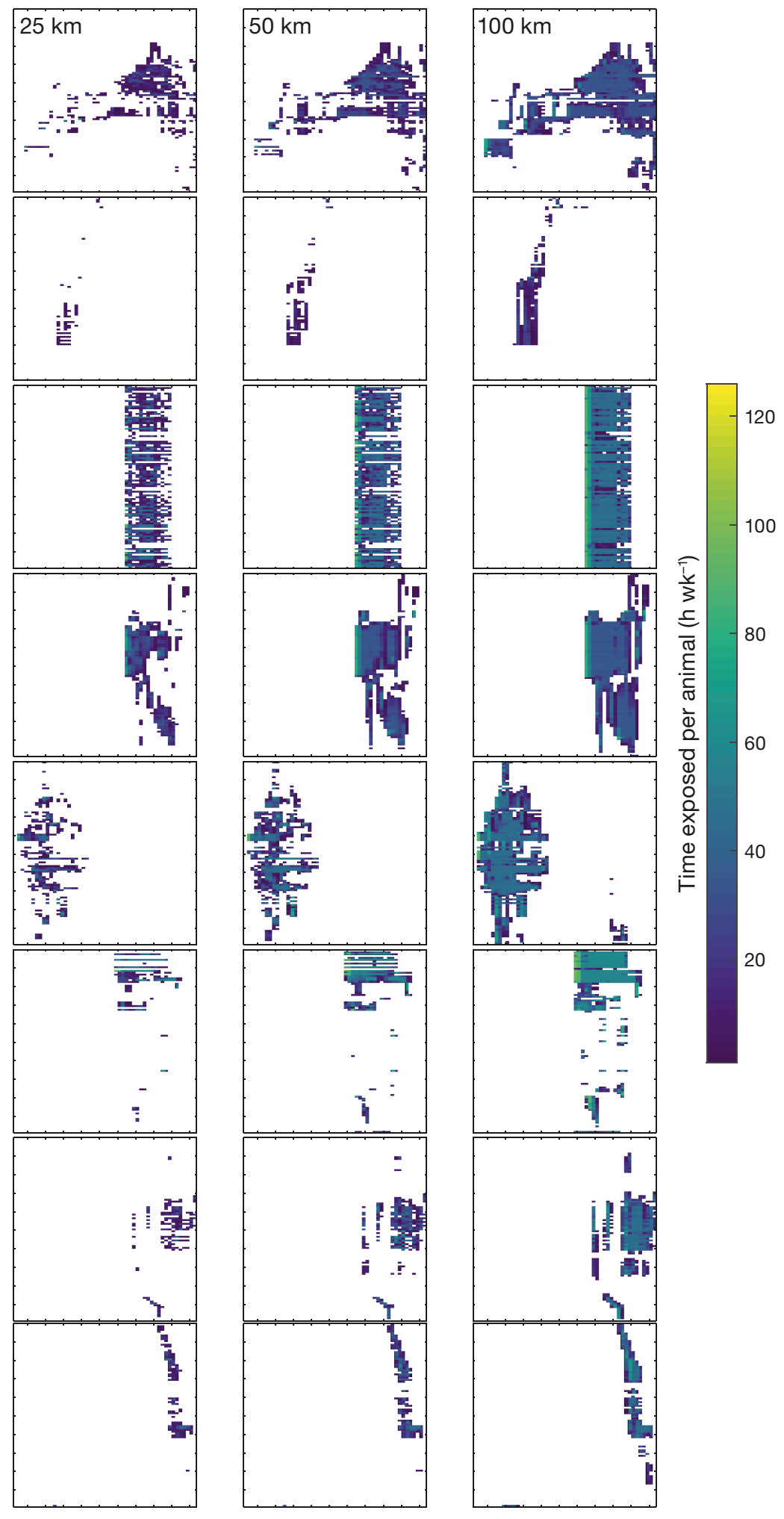

Week of the year (1-52) versus survey number

Fig. 5. Variability in mean individual time exposed $\left(\mathrm{h} \mathrm{wk}^{-1}\right)$ to simulated seismic surveys for blue and humpback whales across one year for (A) 4D and (B) 3D surveys. Each panel corresponds to a different radius of influence (5, 25, 50 and 100 km). Warmer colors indicate longer exposures, with a possible maximum of $126 \mathrm{~h} \mathrm{wk}^{-1}$. For site abbreviations, see Fig. 1 legend 

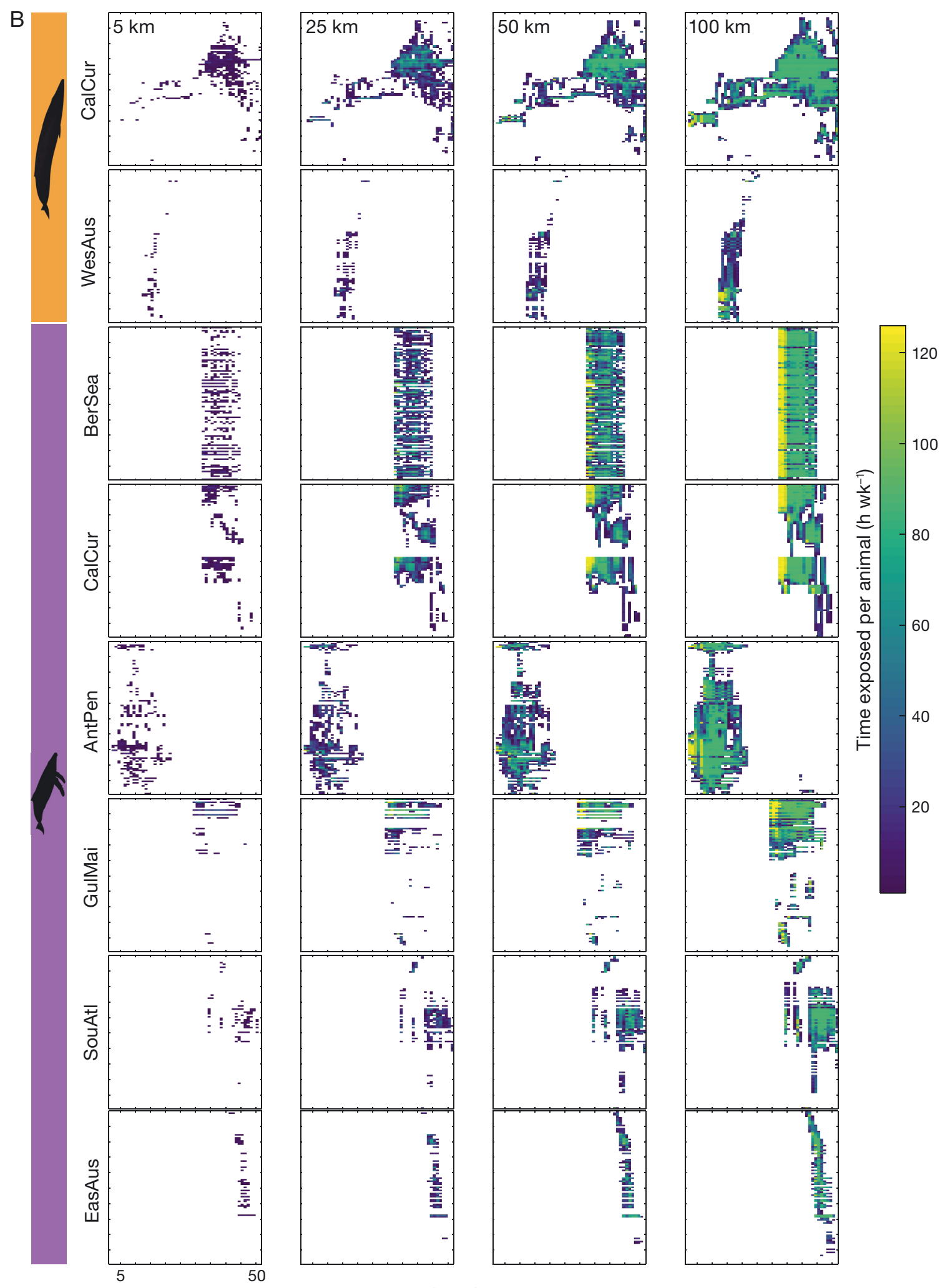

Week of the year (1-52) versus survey number

Fig. 5 (continued) 
behaviors are yet to be determined, it is evident that we need to consider the effects of disturbances beyond the traditional view that has focused on high usage areas (Costa et al. 2016a, Ellison et al. 2016, Guerrini et al. 2019).

A fully implemented seismic survey usually operates an array of air guns that produce noise every 1-15 s, at a source spectral level that ranges between 1 and $100 \mathrm{~Hz}$ of about $205-255 \mathrm{~dB}$ re. $1 \mu \mathrm{Pa}$ at $1 \mathrm{~m}$ (Myrberg 1990, Nowacek et al. 2015). Regardless of the dimensions of the survey (4D or 3D for this study, see Section 2), the source of noise can affect an area during a period of weeks. Thus, the temporal and spatial scales of such sources of disturbance match the scale over which a wide diversity of large and medium-sized marine vertebrates operate. In this study, we take an alternative approach and depart from studies that focus on highly resident species of restricted range, such as harbor porpoises Phocoena phocoena and harbor seals Phoca vitulina (Myrberg 1990, Harwood 2001, Bain \& Williams 2006, Tougaard et al. 2009), and instead estimate the exposure risk for several populations of 2 species of large migratory whales.

Both blue and humpback whales have a wellknown annual life history, breeding in low latitudes and then migrating to mid- and high-latitude highly productive coastal areas to forage, which will influence their potential exposure to disturbance (Costa et al. 2016a). Despite the differences in their movement patterns, we found that, when affected, most individuals in our study had probabilities of exposure that ranged between 0.02 and 0.32 , depending on the population in question (Tables 1 and 2, Figs. 3, 4 and 6). Humpback whales from the Bering Sea, where the data only included movements at foraging grounds, were the exception, having the most constrained distribution across data sets and exposure probabilities that clustered in the 0.31 and 0.81 range (25th and 75th quartiles) (Fig. 3).

Several studies have suggested that seismic survey air gun noise does not elicit a behavioral response from large baleen whales (e.g. cause them to leave the area) unless individuals are within 15-20 km of the source (Myrberg 1990, McDonald et al. 1995, McCauley et al. 2000), although their acoustic behavior is likely affected at longer distances (Di Iorio \& Clark 2009, Cerchio et al. 2014). By using empirical tracks of individuals along with realistic seismic survey scenarios, our methods provide the next step in realistically determining the overlap between surveys and several whale populations. However, our methods only provide an estimate for the maximum amount of exposure since we did not account for animals moving away from the sound source. Future efforts could increase complexity by integrating sound sourceanimal overlap with dose-response curves (probability of moving away from a sound and the distance traveled) to determine actual lost foraging time (Table 2). Across the different data sets used in this study, blue whales from western Australia were unique in their relatively low duration of exposure to seismic surveys, if we consider radii of influence of 5 and $25 \mathrm{~km}$ (Table 2). Perhaps more interestingly, however, is the fact that for all other populations, a radius of $25 \mathrm{~km}$ was enough to expose individual whales at a near-maximum duration (126 h), with only a marginal increase in the maximum duration of the exposure if the radius is increased to 50 or $100 \mathrm{~km}$ (Table 2).

To better visualize the potential effect of seismic surveys on the different populations of whales, we analyzed the relationship between time spent in HR under exposure versus the probability of the population being affected by the different surveys (Fig. 6). The area and shape of the minimum convex polygons (MCPs) for these plots can be used as an indicator of the potential impact for each population.

At one end of the spectrum, blue whales from western Australia showed a clear effect of the survey design and radius of influence on the impact of the surveys. As the radius increases, so does the potential effect of the survey, and 3D surveys (the largest) caused longer maximum exposures to the seismic surveys (Fig. 6C,D). At the other end of the spectrum, highly restricted humpback whales from the Bering Sea showed MCPs elongated along the $y$-axis (proportion of tagged individuals disturbed), indicating that even small radii (5 and $25 \mathrm{~km}$ ) have the possibility to affect most of the population $(>0.6)$ (Fig. 6E,F). Indeed, $100 \%$ of the Bering Sea whales could be exposed for as long as $50 \mathrm{~h}$ (Fig. 6F). Interestingly, humpback whales off the Gulf of Maine, the second most restricted in terms of their movement patterns, only had an elevated potential of exposure to seismic surveys for the largest radii (50 and $100 \mathrm{~km}$ ) (Fig. 6K,L). The differences among the different data sets included in our study are likely associated with a combination of factors, from the spatial spread in the surveys due to the different extension of the continental shelf habitat utilized by each population, to differences in the behavior of individuals among populations. For instance, humpback whales in the Bering Sea had one of the smallest home ranges across data sets and yet most individuals displayed similar patterns of habitat utilization, which 

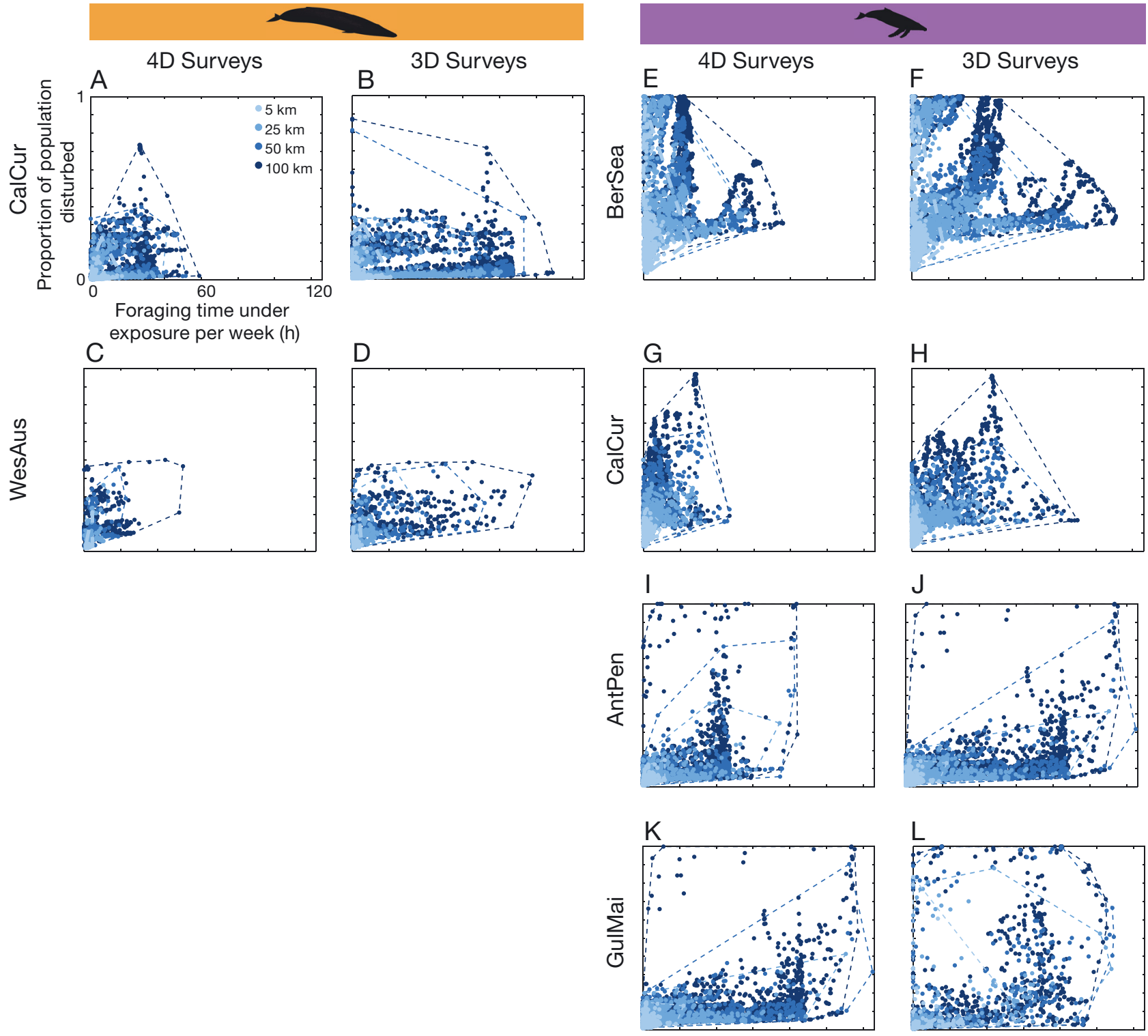

Fig. 6. Potential impacts of simulated surveys for blue whales (yellow) and humpback whales (purple) illustrated as the relationship between the proportion of the tagged individuals exposed and the time under exposure in high residence (HR) behavior. Each dot corresponds to a specific transect-week of the year combination, and the dashed lines represent the minimum convex polygon, indicating the total range of potential impacts. The tones of blue represent the radius of influence, with the lightest blue representing $5 \mathrm{~km}$ and the darkest corresponding to $100 \mathrm{~km}$. Left panels (A, C, E, G, I, K, $\mathrm{M}$ and $\mathrm{O}$ ) correspond to the smaller 4D surveys. Right panels (B, D, F, H, J, L, N and P) correspond to the larger 3D surveys. For site abbreviations, see Fig. 1 legend
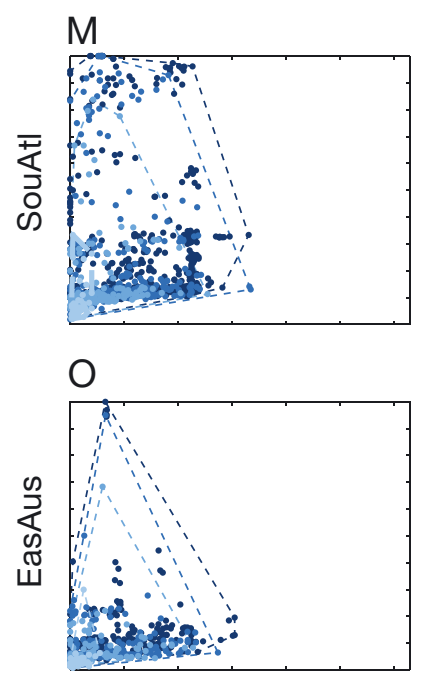

N

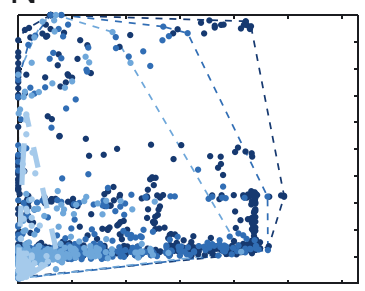

$P$

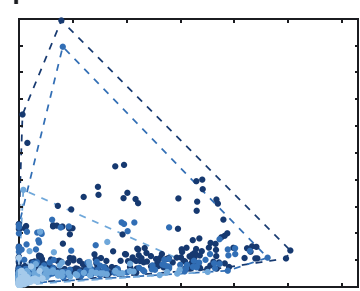


likely drove the elevated impacts observed for this data set. Additionally, differences in sample size can also influence these results.

To assess the effects of anthropogenic noise on marine animals, it is necessary to have information available at the appropriate time and spatial scales (Myrberg 1990). Consequently, the PCoD/PCoMS framework requires spatially explicit information on the abundance and distribution of marine mammals and how these are linked to individual behavioral responses (Bailey et al. 2014, Costa et al. 2016a, Harwood et al. 2016). Furthermore, there is an urgent need to better anticipate the impact of anthropogenic activities and to understand how susceptibility of particular populations varies across space and time.

While our analysis is a basic exercise based on simulated surveys and assumes that whales do not alter their behavior, our results highlight the importance of understanding the behavior and ecology of individuals in a site-specific context when considering the likelihood of exposure to anthropogenic disturbances. For instance, our approach allowed us to identify the temporal variability in the susceptibility of the different populations under study, as we ran the simulations for an entire year, enabling us to identify periods when the surveys would have an intensified effect on whales (warmer colors, Fig. 5A,B). This, however, is invariably a function of the sample size and length of the tracking data set. Blue whales in the California Current had the largest and longest data set, allowing us to robustly detect variations in the susceptibility across the range of the population and almost for a full year, whereas the Bering Sea or Eastern Australia humpback whales data sets offer a limited glimpse of the potential impacts of seismic surveys (Fig. 5A,B, Fig. S2). If we aim at understanding how human activities can potentially affect different populations of marine animals, we need a more complete picture of their movement patterns across an entire annual cycle (i.e. larger and longer tracking data sets).

Traditionally, data on the range, abundance and distribution of species that are being exposed to a source of noise have been collected using visual surveys (Bailey et al. 2014). While these data are valuable and can be very informative to discern behavioral responses of animals under exposure, there are intrinsic biases that limit the application of survey data (e.g. detection probability, spatial range of the observations, and transect design, among others) (Palka \& Hammond 2001, Hammond et al. 2002, Bombosch et al. 2014). Tracking data, in contrast, have the potential to provide unbiased information about the movement patterns of animals at much longer scales and over prolonged periods. Furthermore, the development of new statistical tools now allows us to infer behavioral stages from tracking data (Jonsen et al. 2005, Michelot et al. 2017, McClintock \& Michelot 2018), giving us the ability to link habitat usage with at-sea behavior.

Similarly to seismic surveys, other anthropogenic stressors in the oceans (e.g. shipping, fishing, recreational boating) are dynamic in space and time (Weilgart 2007, Gomez et al. 2016). There is also an increasing pressure to consider temporal changes in the ocean's conditions and human activities to implement better protection measures (Hyrenbach et al. 2000, Maxwell et al. 2015). Our modeling approach can easily be adjusted to be applied to real-world scenarios where there is a need to evaluate the impact of other sources of noise or to assess the effectiveness of mitigation measurements (e.g. postponing a survey, reducing the number of transect lines, or moving a shipping route offshore). The strength of this approach lies in the fact that it acknowledges that the sources of exposure, as well as the animals, are dynamic, making it a more realistic way to understand how anthropogenic activities could affect natural populations of marine animals, and how protection can be implemented. Future iterations should also consider the possibility of combining the likelihood of exposure, as defined in this study, with dynamic species modeling forecasts similar to tools already available to minimize fisheries interactions (Hazen et al. 2018). This would provide near realtime predictions of occurrence, given particular environmental covariates, along with a context-specific assessment of the likelihood of exposure at relevant spatial and temporal scales, improving our ability to minimize the impact of seismic surveys.

We demonstrate that, by using tracking data, we can estimate the maximum likelihood of exposure to simulated moving sources of disturbance, providing us with an estimate of (1) the proportion of individuals that would be exposed, (2) the time for which individuals would be exposed and (3) the behavior affected by the disturbance. This information is a pivotal first step (Fig. S1) toward evaluating populationlevel impacts of a disturbance. These results can then be used (along with data from behavioral response studies, metabolic rate prey availability studies, among others) to estimate the costs of that disturbance on an individual's energy budget, including the amount of energy expended but not acquired, the additional time an individual would have to spend foraging to offset this lost foraging time, and the sub- 
sequent effects on offspring growth and survival (National Research Council 2003, New et al. 2013, Costa et al. 2016a,b).

Acknowledgements. This work was developed in association with the Office of Naval Research-supported PCAD/ PCOD working group and was supported by Office of Naval Research grant N00014-08-1-1195, and the E\&P Sound and Marine Life Joint Industry Project of the International Association of Oil and Gas Producers (JIP 00 07-23). Tagging research in the Gulf of Maine was supported by the National Oceanographic and Atmospheric Administration and ExxonMobile Exploration Company via the National Fish and Wildlife Foundation and the National Oceanographic Partnership Program. Tagging research of blue and humpback whales in the California Current was supported in part by the Tagging of Pacific Pelagics, Office of Naval Research (grant N00014-09-1-0453) and donors to Oregon State University Endowments for Marine Mammal Research and the Marine Mammal Institute. Tagging in the western South Atlantic was funded by Shell Brasil with grants provided to Biodinâmica and Instituto Aqualie. Tagging in the Bering Sea was funded by the former Minerals Management Service (now Bureau of Ocean Energy Management) with grants to the Marine Mammal Laboratory, Alaska Fisheries Science Center. The scientific results and conclusions, as well as any views or opinions expressed herein, are those of the author(s) and do not necessarily reflect those of NOAA or the US Department of Commerce.

\section{LITERATURE CITED}

Bailey H, Mate BR, Palacios DM, Irvine L, Bograd SJ, Costa DP (2009) Behavioural estimation of blue whale movements in the Northeast Pacific from state-space model analysis of satellite tracks. Endang Species Res 10:93-106

Bailey H, Brookes KL, Thompson PM (2014) Assessing environmental impacts of offshore wind farms: lessons learned and recommendations for the future. Aquat Biosyst 10:8

Bain DE, Williams R (2006) Long-range effects of airgun noise on marine mammals: responses as a function of received sound level and distance. IWC Scientific Committee, St Kitts and Nevis, West Indies

Bombosch A, Zitterbart DP, Van Opzeeland I, Frickenhaus S, Burkhardt E, Wisz MS, Boebel O (2014) Predictive habitat modelling of humpback (Megaptera novaeangliae) and Antarctic minke (Balaenoptera bonaerensis) whales in the Southern Ocean as a planning tool for seismic surveys. Deep Sea Res I 91:101-114

Cerchio S, Strindberg S, Collins T, Bennett C, Rosenbaum H (2014) Seismic surveys negatively affect humpback whale singing activity off northern Angola. PLOS ONE 9: e86464

Clapham PJ, Young SB, Brownell RL Jr (1999) Baleen whales: conservation issues and the status of the most endangered populations. Mammal Rev 29:37-62

Costa DP, Hückstädt LA, Schwarz LK, Friedlaender AS and others (2016a) Assessing the exposure of animals to acoustic disturbance: towards an understanding of the population consequences of disturbance. Proc Meetings Acoustics 27:010027

Costa DP, Schwarz L, Robinson P, Schick RS and others (2016b) A bioenergetics approach to understanding the population consequences of disturbance: elephant seals as a model system. In: Popper A, Hawkins A (eds) The effects of noise on aquatic life II. Advances in experimental medicine and biology, Vol 875. Springer, New York, NY, p 161-169

Costanza R (1999) The ecological, economic, and social importance of the oceans. Ecol Econ 31:199-213

de Castro FR, Mamede N, Danilewicz D, Geyer Y, Pizzorno JLA, Zerbini AN, Andriolo A (2014) Are marine protected areas and priority areas for conservation representative of humpback whale breeding habitats in the western South Atlantic? Biol Conserv 179:106-114

* Di Iorio L, Clark CW (2009) Exposure to seismic survey alters blue whale acoustic communication. Biol Lett 6: $51-54$

*Double MC, Andrews-Goff V, Jenner KCS, Jenner MN, Laverick SM, Branch TA, Gales NJ (2014) Migratory movements of pygmy blue whales (Balaenoptera musculus brevicauda) between Australia and Indonesia as revealed by satellite telemetry. PLOS ONE 9:e93578

Ellison WT, Racca R, Clark CW, Streever B and others (2016) Modeling the aggregated exposure and responses of bowhead whales Balaena mysticetus to multiple sources of anthropogenic underwater sound. Endang Species Res 30:95-108

Erbe C (2012) Effects of underwater noise on marine mammals. In: Popper AN, Hawkins A (eds) The effects of noise on aquatic life. Advances in experimental medicine and biology, Vol 730. Springer, New York, NY, p 17-22

*Friedlaender AS, Hazen EL, Goldbogen JA, Stimpert AK, Calambokidis J, Southall BL (2016) Prey-mediated behavioral responses of feeding blue whales in controlled sound exposure experiments. Ecol Appl 26:1075-1085

Goldbogen JA, Southall BL, DeRuiter SL, Calambokidis J and others (2013) Blue whales respond to simulated midfrequency military sonar. Proc Biol Sci 280:20130657

*Gomez C, Lawson JW, Wright AJ, Buren AD, Tollit D, Lesage V (2016) A systematic review on the behavioural responses of wild marine mammals to noise: the disparity between science and policy. Can J Zool 94:801-819

*Guerrini F, Mari L, Casagrandi R (2019) Modelling plastics exposure for the marine biota: risk maps for fin whales in the Pelagos Sanctuary (North-Western Mediterranean). Front Mar Sci 6:299

Halpern BS, Walbridge S, Selkoe KA, Kappel CV and others (2008) A global map of human impact on marine ecosystems. Science 319:948-952

* Halpern BS, Frazier M, Potapenko J, Casey KS and others (2015) Spatial and temporal changes in cumulative human impacts on the world's ocean. Nat Commun 6:7615

* Hammond P, Berggren P, Benke H, Borchers D and others (2002) Abundance of harbour porpoise and other cetaceans in the North Sea and adjacent waters. J Appl Ecol 39:361-376

* Harwood J (2001) Marine mammals and their environment in the twenty-first century. J Mammal 82:630-640

*Harwood J, King S, Booth C, Donovan C, Schick RS, Thomas L, New L (2016) Understanding the population consequences of acoustic disturbance for marine mammals. In: Popper AN, Hawkins A (eds) The effects of noise on aquatic life II. Advances in experimental medicine and biology, Vol 875. Springer, New York, NY, p 417-423

*Hazen EL, Scales KL, Maxwell SM, Briscoe DK and others (2018) A dynamic ocean management tool to reduce bycatch and support sustainable fisheries. Sci Adv 4: eaar3001 
Hyrenbach KD, Forney KA, Dayton PK (2000) Marine protected areas and ocean basin management. Aquat Conserv 10:437-458

Irvine LM, Mate BR, Winsor MH, Palacios DM, Bograd SJ, Costa DP, Bailey H (2014) Spatial and temporal occurrence of blue whales off the US West Coast, with implications for management. PLOS ONE 9:e102959

Jackson JB (2001) What was natural in the coastal oceans? Proc Natl Acad Sci USA 98:5411-5418

Johnson DS, London JM, Lea MA, Durban JW (2008) Continuous-time correlated random walk model for animal telemetry data. Ecology 89:1208-1215

Jonsen ID, Flemming JM, Myers RA (2005) Robust statespace modeling of animal movement data. Ecology 86: 2874-2880

Kennedy AS, Zerbini AN, Rone BK, Clapham PJ (2014) Individual variation in movements of satellite-tracked humpback whales Megaptera novaeangliae in the eastern Aleutian Islands and Bering Sea. Endang Species Res 23: 187-195

King SL, Schick RS, Donovan C, Booth CG, Burgman M, Thomas L, Harwood J (2015) An interim framework for assessing the population consequences of disturbance. Methods Ecol Evol 6:1150-1158

Madsen PT (2005) Marine mammals and noise: problems with root mean square sound pressure levels for transients. J Acoust Soc Am 117:3952-3957

Maxwell SM, Hazen EL, Bograd SJ, Halpern BS and others (2013) Cumulative human impacts on marine predators. Nat Commun 4:2688

* Maxwell SM, Hazen EL, Lewison RL, Dunn DC and others (2015) Dynamic ocean management: defining and conceptualizing real-time management of the ocean. Mar Policy 58:42-50

McCauley R, Fewtrell J, Duncan A, Jenner C and others (2000) Marine seismic surveys - a study of environmental implications. APPEA J 40:692-708

* McClintock BT, Michelot T (2018) momentuHMM R package for generalized hidden Markov models of animal movement. Methods Ecol Evol 9:1518-1530

McConnell BJ, Chambers C, Fedak MA (1992) Foraging ecology of southern elephant seals in relation to the bathymetry and productivity of the Southern Ocean. Antarct Sci 4:393-398

McDonald MA, Hildebrand JA, Webb SC (1995) Blue and fin whales observed on a seafloor array in the Northeast Pacific. J Acoust Soc Am 98:712-721

Merrie A, Dunn DC, Metian M, Boustany AM and others (2014) An ocean of surprises - trends in human use, unexpected dynamics and governance challenges in areas beyond national jurisdiction. Glob Environ Change 27:19-31

Michelot T, Langrock R, Bestley S, Jonsen ID, Photopoulou T, Patterson TA (2017) Estimation and simulation of foraging trips in land-based marine predators. Ecology 98: 1932-1944

Myrberg AA Jr (1990) The effects of man-made noise on the behavior of marine animals. Environ Int 16:575-586

National Academies of Sciences, Engineering, and Medicine (2017) Approaches to understanding the cumulative effects of stressors on marine mammals. National Academies Press, Washington, DC

National Research Council (2003) Ocean noise and marine mammals. National Academies Press, Washington, DC

National Research Council (2005) Marine mammal populations and ocean noise: determining when noise causes

Editorial responsibility: Bryan P. Wallace,

Fort Collins, CO, USA biologically significant effects. National Academies Press, Washington, DC

New LF, Moretti DJ, Hooker SK, Costa DP, Simmons SE (2013) Using energetic models to investigate the survival and reproduction of beaked whales (family Ziphiidae). PLOS ONE 8:e68725

New LF, Clark JS, Costa DP, Fleishman E and others (2014) Using short-term measures of behaviour to estimate long-term fitness of southern elephant seals. Mar Ecol Prog Ser 496:99-108

* Nowacek DP, Clark CW, Mann D, Miller PJO and others (2015) Marine seismic surveys and ocean noise: time for coordinated and prudent planning. Front Ecol Environ 13:378-386

* Palka D, Hammond P (2001) Accounting for responsive movement in line transect estimates of abundance. Can J Fish Aquat Sci 58:777-787

*Pirotta E, Mangel M, Costa DP, Mate B and others (2018) A dynamic state model of migratory behavior and physiology to assess the consequences of environmental variation and anthropogenic disturbance on marine vertebrates. Am Nat 191:E40-E56

R Development Core Team (2019) R: a language and environment for statistical computing. R Foundation for Statistical Computing, Vienna

Ray GC (1988) Ecological diversity in coastal zones and oceans. In: Wilson EO, Peter FM (eds) Biodiversity. National Academies Press, Washington, DC, p 36-50

* Sherman K (1994) Sustainability, biomass yields, and health of coastal ecosystems: an ecological perspective. Mar Ecol Prog Ser 112:277-301

* Southall BL, Moretti D, Abraham B, Calambokidis J, DeRuiter SL, Tyack PL (2012) Marine mammal behavioral response studies in southern California: advances in technology and experimental methods. Mar Technol Soc J 46:48-59

Southall BL, Nowacek DP, Miller PJO, Tyack PL (2016) Experimental field studies to measure behavioral responses of cetaceans to sonar. Endang Species Res 31: 293-315

Thomas PO, Reeves RR, Brownell RL (2016) Status of the world's baleen whales. Mar Mamm Sci 32:682-734

* Tougaard J, Carstensen J, Teilmann J, Skov H, Rasmussen P (2009) Pile driving zone of responsiveness extends beyond $20 \mathrm{~km}$ for harbor porpoises (Phocoena phocoena (L.)). J Acoust Soc Am 126:11-14

Van der Hoop JM, Moore MJ, Barco SG, Cole TV and others (2013) Assessment of management to mitigate anthropogenic effects on large whales. Conserv Biol 27:121-133

*Weilgart LS (2007) The impacts of anthropogenic ocean noise on cetaceans and implications for management. Can J Zool 85:1091-1116

Weinstein BG, Irvine L, Friedlaender AS (2018) Capturing foraging and resting behavior using nested multivariate Markov models in an air-breathing marine vertebrate. Mov Ecol 6:16

K Zerbini AN, Andriolo A, Heide-Jørgensen MP, Pizzorno JL and others (2006) Satellite-monitored movements of humpback whales Megaptera novaeangliae in the Southwest Atlantic Ocean. Mar Ecol Prog Ser 313:295-304

Zerbini AN, Andriolo A, Heide-Jørgensen MP, Moreira SC and others (2011) Migration and summer destinations of humpback whales (Megaptera novaeangliae) in the western South Atlantic Ocean. J Cetacean Res Manag 3: $113-118$

Submitted: January 3, 2020; Accepted: June 18, 2020

Proofs received from author(s): August 17, 2020 